\title{
Passive exposure to e-cigarette emissions: Immediate respiratory effects
}

\author{
Anna Tzortzi ${ }^{1,2}$, Stephanie I. Teloniatis ${ }^{1}$, George Matiampa', Gerasimos Bakelas' ${ }^{1}$, Vergina K. Vyzikidou', Constantine \\ Vardavas ${ }^{1,2}$, Panagiotis K. Behrakis ${ }^{1,2}$, Esteve Fernandez ${ }^{3,4}$
}

\begin{abstract}
INTRODUCTION The present work examined the effect of passive exposure to electronic-cigarette (e-cigarette) emissions on respiratory mechanics and exhaled inflammatory biomarkers.

METHODS A cross-over experimental study was conducted with 40 healthy nonsmokers, 18-35 years old with normal physical examination and spirometry, with body mass index $<30 \mathrm{~kg} / \mathrm{m}^{2}$, who were exposed to e-cigarette emissions produced by a smoker, according to a standardized protocol based on two resistance settings, $0.5 \mathrm{ohm}$ and $1.5 \mathrm{ohm}$, for e-cigarette use. All participants underwent a 30-minute control (no emissions) and two experimental sessions ( 0.5 and $1.5 \mathrm{ohm}$ exposure) in a $35 \mathrm{~m}^{3}$ room. The following Impulse Oscillometry (IOS) parameters were measured at pre and post sessions: impedance, resistance, reactance, resonant frequency (fres), frequency dependence of resistance $(f d r=\mathrm{R} 5-\mathrm{R} 20)$, reactance area $(\mathrm{AX})$, and fractional exhaled nitric oxide (FeNO). Differences between pre and post measurements were compared using t-tests and Wilcoxon signed rank tests, while analysis of variance (ANOVA) was used for comparisons between experimental sessions (registered under ClinicalTrials.gov ID: NCT03102684).

RESULTS IOS and FeNO parameters showed no significant changes during the control session. For IOS during the $1.5 \mathrm{ohm}$ exposure session, fres increased significantly from $11.38 \mathrm{~Hz}$ at baseline to $12.16 \mathrm{~Hz}$ post exposure $(\mathrm{p}=0.047)$. FeNO decreased significantly from $24.16 \mathrm{ppb}$ at baseline to $22.35 \mathrm{ppb}$ post exposure in the $0.5 \mathrm{ohm}$ $\operatorname{session}(\mathrm{p}=0.006)$.

CONCLUSIONS A 30-minute passive exposure to e-cigarette emissions revealed immediate alterations in respiratory mechanics and exhaled biomarkers, expressed as increased fres and reduced FeNO.
\end{abstract}

AFFILIATION

1 George D. Behrakis Research Lab, Hellenic Cancer Society,

Athens, Greece

2 Institute of Public Health,The American College of Greece,

Athens, Greece

3 Tobacco Control Unit, Institut Català d'Oncologia (ICO) and Institut d'Investigació Bioomèdica de Bellvitge (IDIBELL), L'Hospitalet de Llobregat, Barcelona, Spain 4 Department of Clinical Sciences, School of Medicine and Health Sciences, Campus de Bellvitge, Universitat de Barcelona, L'Hospitalet de Llobregat, Barcelona, Spain

\section{CORRESPONDENCE TO}

Anna Tzortzi. George D. Behrakis Research Lab, Hellenic Cancer Society, 17b Ipitou, 105 57 Athens, Greece.

E-mail: atzortzi@researchlab.gr

KEYWORDS

nitric oxide, e-cigarette, passive, respiratory resistance, second-hand aerosol

Received: 26 March2017 Revised: 16 April 2018

Accepted: 16 April 2018

\section{INTRODUCTION}

The adverse health effects of passive exposure to conventional cigarette smoke have been extensively studied and are well documented ${ }^{1}$. After 10 years of experience with electronic cigarettes (e-cigarettes) ${ }^{2}$ it is known that its active use is associated with immediate adverse health effects ${ }^{3-9}$. However, limited studies have evaluated the potential impact on indoor air quality, as well as the health effects of exposure to second-hand aerosols from e-cigarettes ${ }^{6,9-16}$. Most studies that have examined passive exposure to e-cigarette emissions have several limitations, such as small sample sizes, use of smoking machines instead of humans, use of cell cultures or animal 
models, varying e-cigarette devices, environment and methodologies, or lacked standardization of e-cigarette topography ${ }^{2,6,7,14}$. Only two studies have examined biomarkers in humans, such as blood count and cotinine in saliva and urine ${ }^{16,17}$, while only one study ${ }^{15}$ examined respiratory effects in terms of spirometry and FeNO.

E-cigarette liquid is a solution that usually contains nicotine, glycerol, propylene glycol and various flavour additives ${ }^{18}$. When thermally treated, it emits what is commonly referred to as a 'vapour', which is in fact a fine aerosol consisting of liquid and solid particles, dispersed in a gas ${ }^{18}$. Following inhalation using the e-cigarette, the aerosol is delivered into the user's lungs, while during expiration the remaining aerosol is exhaled into the environment ${ }^{18}$, forming an unintentional pollution source of particulate matter (second-hand aerosol or SHA) to which bystanders are potentially exposed ${ }^{6,19}$.

A study by Schripp et al. ${ }^{10}$ concluded that the size distribution of aerosol particles is altered once it enters the user's lungs, mainly due to their 'shrinking' by evaporation of the liquid, finally leading to the exhalation of even smaller particles back into the environment ${ }^{10}$. These smaller particles (fine and ultrafine) released into the environment are a concern in terms of passive exposure given their ability to enter into the alveoli and ultimately into the circulatory system ${ }^{20}$.

In addition, Lerner et al. ${ }^{21}$ found that the e-cigarette aerosol modified the levels of oxidative stress and inflammatory biomarkers in human airway epithelial cells. They also reported un-vaporized e-cigarette liquid was associated with oxidative reactivity attributed to flavour additives; the sweet and fruit additives having been found to exhibit stronger oxidation than the tobacco flavours ${ }^{21}$.

Given the increasing popularity of e-cigarette use, limitations of existing studies and the lack of clinical studies on humans, especially with regard to lung function, our aim was to assess the effect of passive exposure to e-cigarette emissions on respiratory mechanics and exhaled biomarkers among young healthy adults. Furthermore, the study aimed to replicate realistic conditions of e-cigarette use and exposure.

The current study was developed in the frame of the project Tackling second-hand tobacco smoke and e-cigarette emissions: Exposure assessment, novel interventions, impact on lung diseases and economic burden in diverse European populations (TackSHS), with the aim to improve our understanding of the possible health effects of second-hand exposure ${ }^{22}$.

\section{METHODS}

\section{Study design}

An experimental, cross-over, laboratory-based study was designed to measure passive exposure of nonsmokers to e-cigarette emissions. The experiment included three sessions on three different days: a control session with no emissions and two experimental sessions, conducted with a 2 -day interval between them. Each participant underwent the sessions one at a time being exposed for 30 minutes in a room measuring $35 \mathrm{~m}^{3}$. IOS and FeNO were measured in all sessions before and immediately after the 30-minute exposure.

For the control session, participants remained in the room for 30 minutes with the active e-cigarette user present without activating the e-cigarette. During the experimental sessions, an experienced e-cigarette user familiar with a new-generation e-cigarette device, produced aerosol emissions, according to a standardized protocol for settings, topography and e-cigarette liquid. According to manufacturer's recommendations, the e-cigarette with the $0.5 \mathrm{ohm}$ resistance was set at 22.5 watts ( $0.5 \mathrm{ohm}$ session), while the e-cigarette with the $1.5 \mathrm{ohm}$ resistance was set at 14.0 watts $(1.5 \mathrm{ohm}$ session). Topography for smoking was 4-second puffs with 20-30 second inter-puff intervals using the same e-cigarette device for all sessions ${ }^{23-25}$. The same tobacco flavored e-cigarette liquid was used for exposure sessions, containing propylene glycol $46.13 \% \mathrm{w} / \mathrm{v}$, glycerol $34.3 \% \mathrm{w} / \mathrm{v}$, nicotine $1.18 \% \mathrm{w} / \mathrm{v}$ and tobacco essence $(<5 \% \mathrm{w} / \mathrm{v})^{26}$.

\section{Participants}

Volunteer participants were recruited by wordof-mouth and posted invitations at universities in Athens, Greece, from March to July 2017. A total of 40 non-smokers (20 male and 20 female) aged 18-35 years, healthy (with non-significant medical history, normal physical examination and flow-volume loop within predicted normal limits according to the American Thoracic Society/ 
European Respiratory Society [ATS/ERS] Task Force 2005) and body mass index (BMI) $<30 \mathrm{~kg} /$ $\mathrm{m}^{2}$, were included in the current study. Exclusion criteria included current (daily or occasional) smokers, former smokers (having quit smoking less than 1 year prior to the study), age under 18 or over 35 year, BMI $>30 \mathrm{~kg} / \mathrm{m}^{2}$, pregnancy or lactation, any ongoing or recent illness or infection $(<4$ weeks prior to study), acute or chronic conditions, and any use of medication ( $<2$ weeks prior to study). All participants were instructed to fast for two hours prior to each session ${ }^{27}$.

\section{Ethical and legal aspects}

Volunteer participants were informed of the scope of the study and their right to access and withdraw at any time. Each participant gave their written informed consent prior to beginning the study. Ethics approval was granted from the Ethics Committee of the School of Medicine, National Kapodistrian University of Athens (protocol: 1617006410), and the study was registered in clinicaltrials.gov (ID NCT03102684).

\section{Measurement of respiratory parameters}

Flow-volume loop and exhaled carbon monoxide (eCO)

Baseline flow volume was performed prior to study sessions as a prerequisite for inclusion. The maneuver was performed in a sitting position with a nose-clip applied using a Jaeger MasterScreen Spirometry system (Franklin Lake, NJ, USA). Forced vital capacity (FVC), forced expiratory volume in the first second $\left(\mathrm{FEV}_{1}\right)$, Tiffeneau Index $\left(\mathrm{FEV}_{1} / \mathrm{FVC} \%\right)$, peak expiratory flow (PEF) and mid-expiratory flows (FEF at $25 \%, 50 \%$ and $75 \%$ of exhaled FVC) were measured along with their predictive values calculated by computer software.

Using a Bedfont ${ }^{\circledR}$ Scientific Ltd. Micro+ ${ }^{\mathrm{m}}$ Smokerlyzer ${ }^{\circledR}$ (Harrietsham, Maidstone, Kent) calibrated according to manufacturer's guidelines, eCO was measured prior to each session with inclusion $<7 \mathrm{ppm}^{28}$ to ensure non-smoking status and absence of exposure prior to beginning each session. With a nose-clip applied, participants were instructed to inhale and hold their breath for approximately 15 seconds and then exhale into the mouthpiece for approximately 10 seconds $^{28}$.

\section{Impulse oscillometry}

Impedance at $5 \mathrm{~Hz}(\mathrm{Z} 5)$, resistance at 5,10 and $20 \mathrm{~Hz}$ (R5, R10 and R20), reactance at $5 \mathrm{~Hz}$ (X5), resonant frequency (fres), frequency dependence of resistance $(f d r)$ and reactance area (AX) were measured using a Viasys Jaeger Masterscreen IOS system (Franklin Lake, NJ, USA). In an upright sitting position with a nose-clip applied and cheeks lightly supported by the participant's hands, the participant was instructed to breathe normally and performed three reproducible trials with intra-assay coefficient of variation (CV) $<10 \%{ }^{29}$.

\section{Fractional exhaled nitric oxide (FeNO)}

Using Eco Medics AG CLD 88 Series chemiluminescence analyzer (Durnten, Switzerland) equipped with a Spiroware 3.0 software program, three reproducible measurements (with intra-assay $\mathrm{CV}<10 \%$ ) were performed in a sitting position with a nose-clip applied. Participants were instructed to deeply inhale through a filtered mouthpiece and consecutively exhale at a mouth flow rate of approximately $50 \mathrm{~mL} / \mathrm{s}$ for 10 seconds.

All procedures were performed according to ATS/ ERS guidelines ${ }^{27,29,30}$.

\section{Statistical analysis}

Demographics and inclusion criteria for the whole sample of 40 young non-smokers were presented as mean and standard deviation (SD). IOS and FeNO measurements were also presented as mean and SD. The differences between pre and post IOS and FeNO measurements were evaluated for significance using Wilcoxon signed-rank test and student t-tests for paired data. Analysis of variance (ANOVA) for repeated measurements was used to assess differences between exposures accounting for differences between pre and post values. To account for multiple comparisons, a Tukey correction was used. All tests were two-tailed and statistical significance was set at $5 \%(\mathrm{p}<0.05)$. Data were analysed using Stata ${ }^{\mathrm{TM}}$ (Version 15.0 SE, Stata Corporation, College Station, TX 77845, USA).

\section{RESULTS}

\section{Demographics and flow-volume loop}

Participants had a mean age of 24.6 years, weight of $71.4 \mathrm{~kg}$, height of $174.1 \mathrm{~cm}$ and BMI of $23.4 \mathrm{~kg}$ / 
$\mathrm{m}^{2}$ (Table 1). Baseline flow-volume loops were within normal limits (Table 1). All exhaled CO measurements were $<7 \mathrm{ppm}$ prior to starting each session with an average of $2.1 \mathrm{ppm}$ in all sessions ranging from 1 to $5 \mathrm{ppm}$. Five of the forty participants were former smokers, with three of them reporting having smoked for under 5 years and the other two for $7-8$ years.

\section{IOS and FeNO}

As shown in Table 2, there was a significant increase in fres in the $1.5 \mathrm{ohm}$ session and a significant decrease in FeNO in the $0.5 \mathrm{ohm}$ session, pre to post exposure to SHA from e-cigarettes. Mean value for $\mathrm{Z} 5$ in the control session was $0.40 \mathrm{kPa} / \mathrm{L} / \mathrm{s}$ pre and $0.41 \mathrm{kPa} / \mathrm{L} / \mathrm{s}$ post exposure, indicating no significant change. In both experimental sessions, Z5 did not change significantly from pre to post exposure.

In the control session, R5 did not change significantly from pre to post exposure $(\mathrm{p}=0.472)$. In the $0.5 \mathrm{ohm}$ session, mean pre and post measurements did not change from $0.39 \mathrm{kPa} / \mathrm{L} / \mathrm{s}$. In the $1.5 \mathrm{ohm}$ session, R5 showed a post exposure decrease trend that was not significant, with mean values of 0.39 pre to $0.38 \mathrm{kPa} / \mathrm{L} / \mathrm{s}$ post exposure (Table 2).
Table 1. Demographics, exhaled carbon monoxide (eCO) prior to sessions and baseline Spirometry among the 40 participants (20 men and 20 women), Athens 2017.

\begin{tabular}{|c|c|c|}
\hline & Mean (SI) & \\
\hline Age (years) & $24.6(4.3)$ & \\
\hline Weight (kg) & $71.4(15.4)$ & \\
\hline Height (cm) & $174.1(10.5)$ & \\
\hline BMI (kg/m2) & $23.4(3.8)$ & \\
\hline \multicolumn{3}{|l|}{ eCO (ppm) } \\
\hline control & $2.1(1.0)$ & \\
\hline $0.5 \mathrm{ohm}$ & $2.2(0.7)$ & \\
\hline $1.5 \mathrm{ohm}$ & $2.0(0.6)$ & \\
\hline Flow volume & & $\%$ Predicted (SD) \\
\hline $\mathrm{FVC}(\mathrm{L})$ & $4.65(1.18)$ & $100.5(10.3)$ \\
\hline $\mathrm{FEV}_{1}(\mathrm{~L})$ & $3.86(0.91)$ & $97.8(10.3)$ \\
\hline $\mathrm{FEV}_{1} / \mathrm{FVC}(\%)$ & na & $83.7(6.2)$ \\
\hline $\mathrm{FEF}_{25 / 75}(\mathrm{~L} / \mathrm{s})$ & $4.09(1.20)$ & $89.1(21.1)$ \\
\hline $\mathrm{FEF}_{25 \%}(\mathrm{~L} / \mathrm{s})$ & 7.74 (1.94) & $104.1(14.7)$ \\
\hline $\mathrm{FEF}_{50 \%}(\mathrm{~L} / \mathrm{s})$ & $5.15(1.50)$ & $99.7(24.7)$ \\
\hline $\mathrm{FEF}_{75 \%}(\mathrm{~L} / \mathrm{s})$ & $2.21(0.76)$ & 89.7 (25.7) \\
\hline PEF(L/s) & $8.29(2.01)$ & $95.6(12.3)$ \\
\hline
\end{tabular}

BMI: Body mass index; SD: standard deviation; FVC: forced vital capacity; FEV1: forced expiratory volume in the first second; Tiffeneau Index: FEV1/FVC\%; Mid-expiratory flows: FEF at 25\%, 50\% and 75\% of exhaled FVC; PEF: peak expiratory flow; na: not applicable.

In both control and $1.5 \mathrm{ohm}$ sessions, R10 and R20 did not change from pre to post (mean 0.34 $\mathrm{kPa} / \mathrm{L} / \mathrm{s})$. During the $0.5 \mathrm{ohm}$ session, $\mathrm{R} 10$ remained

Table 2. Results of Impulse Oscillometry (IOS) and fractional exhaled nitric oxide (FeNO) pre and post all exposure sessions in 40 participants, Athens 2017.

\begin{tabular}{|c|c|c|c|c|c|c|c|}
\hline & Session & Pre & SD & Post & SD & Dill: & $p$ \\
\hline \multirow[t]{3}{*}{$\mathrm{Z5}$ (kPa/L/s) } & control & 0.40 & 0.11 & 0.41 & 0.11 & 0.01 & $0.302^{t}$ \\
\hline & $0.5 \mathrm{ohm}$ & 0.41 & 0.12 & 0.41 & 0.12 & 0.00 & 0.661 \\
\hline & $1.5 \mathrm{ohm}$ & 0.41 & 0.13 & 0.40 & 0.12 & -0.01 & 0.930 \\
\hline \multirow[t]{3}{*}{ R5 (kPa/L/s) } & control & 0.38 & 0.10 & 0.38 & 0.11 & 0.00 & $0.472^{t}$ \\
\hline & $0.5 \mathrm{ohm}$ & 0.39 & 0.11 & 0.39 & 0.12 & 0.00 & 0.638 \\
\hline & $1.5 \mathrm{ohm}$ & 0.39 & 0.13 & 0.38 & 0.12 & -0.01 & 0.721 \\
\hline \multirow[t]{3}{*}{$\mathrm{R} 10$ (kPa/L/s) } & control & 0.34 & 0.09 & 0.34 & 0.09 & 0.00 & $0.291^{\mathrm{t}}$ \\
\hline & $0.5 \mathrm{ohm}$ & 0.35 & 0.10 & 0.35 & 0.10 & 0.00 & 0.540 \\
\hline & $1.5 \mathrm{ohm}$ & 0.34 & 0.11 & 0.34 & 0.10 & 0.00 & 0.377 \\
\hline \multirow[t]{3}{*}{$\mathrm{R} 20$ (kPa/L/s) } & control & 0.34 & 0.08 & 0.34 & 0.09 & 0.00 & $0.580^{t}$ \\
\hline & $0.5 \mathrm{ohm}$ & 0.34 & 0.09 & 0.35 & 0.09 & 0.01 & $0.373^{t}$ \\
\hline & $1.5 \mathrm{ohm}$ & 0.34 & 0.09 & 0.34 & 0.09 & 0.00 & 0.571 \\
\hline Mean R5-R20 & control & 0.36 & 0.09 & 0.36 & 0.09 & 0.00 & $0.495^{t}$ \\
\hline \multirow{2}{*}{$(\mathrm{kPa} / \mathrm{L} / \mathrm{s})$} & $0.5 \mathrm{ohm}$ & 0.36 & 0.10 & 0.37 & 0.11 & 0.01 & 0.340 \\
\hline & $1.5 \mathrm{ohm}$ & 0.36 & 0.11 & 0.36 & 0.10 & 0.00 & 0.584 \\
\hline \multirow[t]{3}{*}{ X5 (kPa/L/s) } & control & -0.11 & 0.04 & -0.11 & 0.04 & 0.00 & $0.819^{t}$ \\
\hline & $0.5 \mathrm{ohm}$ & -0.12 & 0.04 & -0.14 & 0.13 & -0.02 & 0.906 \\
\hline & $1.5 \mathrm{ohm}$ & -0.12 & 0.04 & -0.11 & 0.03 & 0.01 & 0.286 \\
\hline
\end{tabular}


Table 2. Continued

\begin{tabular}{|c|c|c|c|c|c|c|c|}
\hline & Session & Pre & SD & Post & SD & Dill. & p \\
\hline \multirow[t]{3}{*}{ fres $(\mathrm{Hz})$} & control & 11.15 & 3.24 & 11.33 & 3.30 & 0.18 & 0.141 \\
\hline & $0.5 \mathrm{ohm}$ & 11.70 & 3.27 & 11.23 & 2.82 & -0.47 & 0.066 \\
\hline & $1.5 \mathrm{ohm}$ & 11.38 & 3.66 & 12.16 & 4.07 & 0.78 & 0.047 \\
\hline \multirow[t]{3}{*}{$\mathrm{AX}(\mathrm{kPa} / \mathrm{L})$} & control & 0.33 & 0.26 & 0.34 & 0.28 & 0.01 & 0.440 \\
\hline & $0.5 \mathrm{ohm}$ & 0.36 & 0.26 & 0.34 & 0.25 & -0.02 & 0.224 \\
\hline & $1.5 \mathrm{ohm}$ & 0.38 & 0.46 & 0.36 & 0.26 & -0.02 & 0.247 \\
\hline \multirow[t]{3}{*}{ FeNO (ppb) } & control & 26.45 & 0.11 & 25.00 & 0.11 & -1.45 & 0.070 \\
\hline & $0.5 \mathrm{ohm}$ & 24.16 & 0.12 & 22.35 & 0.12 & -1.81 & 0.006 \\
\hline & $1.5 \mathrm{ohm}$ & 24.35 & 0.13 & 23.44 & 0.12 & -0.91 & 0.368 \\
\hline
\end{tabular}

SD: standard deviation; p-values result of Wilcoxon signed rank test unless indicated by t-results of t-test; Diff.: Difference between post and pre exposure.

at $0.35 \mathrm{kPa} / \mathrm{L} / \mathrm{s}$ pre and post exposure, while $\mathrm{R} 20$ increased non-significantly from 0.34 to $0.35 \mathrm{kPa} /$ $\mathrm{L} / \mathrm{s}$ (Table 2). In both control and $1.5 \mathrm{ohm}$ session, mean R5-R20 did not change from $0.36 \mathrm{kPa} / \mathrm{L} / \mathrm{s}$. In the $0.5 \mathrm{ohm}$ session, mean R5-R20 exhibited a nonsignificant increase from 0.36 pre to $0.37 \mathrm{kPa} / \mathrm{L} / \mathrm{s}$ post exposure (Table 2). As shown in Table 2 , X5 did not change in the control session with mean -0.11 $\mathrm{kPa} / \mathrm{L} / \mathrm{s}$. In the $0.5 \mathrm{ohm}$ session, $\mathrm{X} 5$ decreased from -0.12 pre to $-0.14 \mathrm{kPa} / \mathrm{L} / \mathrm{s}$ post exposure, while in the $1.5 \mathrm{ohm}$ session it increased from -0.12 to -0.11 $\mathrm{kPa} / \mathrm{L} / \mathrm{s}$.

In the control and $0.5 \mathrm{ohm}$ sessions, fres did not change significantly $(\mathrm{p}=0.141$ and $\mathrm{p}=0.066$, respectively). In the $1.5 \mathrm{ohm}$ session, fres showed a significant increase of $6.9 \%$ (mean $11.38 \mathrm{~Hz}$ pre and $12.16 \mathrm{~Hz}$ post exposure, $\mathrm{p}=0.047$ ) (Table 2). Pre and post changes differed significantly between the experimental sessions $(\mathrm{p}=0.030)$.

AX did not change significantly from pre to post exposure for all three sessions with mean measurements 0.33 pre to $0.34 \mathrm{kPa} / \mathrm{L} / \mathrm{s}$ post exposure in the control session $(\mathrm{p}=0.440), 0.36$ to $0.34 \mathrm{kPa} / \mathrm{L} / \mathrm{s}$ in the $0.5 \mathrm{ohm}$ session $(\mathrm{p}=0.224)$, and 0.38 to $0.36 \mathrm{kPa} / \mathrm{L} / \mathrm{s}$ in the $1.5 \mathrm{ohm}$ session $(\mathrm{p}=0.247)($ Table 2).

In the $0.5 \mathrm{ohm}$ session, FeNO exhibited a significant decrease of $7.5 \%$ (mean 24.16 ppb pre and $22.35 \mathrm{ppb}$ post exposure, $\mathrm{p}=0.006$ ), whereas in the control and $1.5 \mathrm{ohm}$ sessions it did not change significantly (Table 2 ).

\section{DISCUSSION}

The current study found that passive exposure to SHA produced by e-cigarette users showed minor alterations in respiratory mechanics and exhaled NO of the exposed participants, while the role of the resistance/power settings was found to be inconclusive.

Respiratory mechanics were evaluated by IOS, as it only requires quiet breathing and captures subtle alterations of lung mechanics even when spirometry is still normal ${ }^{31,32}$. IOS captures the nonuniformities in airflow distribution, considered an early manifestation of small-airways disease and so represents an ideal screening tool ${ }^{33}$. The current study found a significant increase in fres after the $1.5 \mathrm{ohm}$ session. It is known that fres decreases with age and increases for both restrictive and obstructive disorders ${ }^{33,34}$. The obstructive airway pattern, expressed with increased fres, AX, R5 and $\mathrm{R} 20$, is evident in asthma where fres, R5 and R20 increase with broncho-provocation and decrease with broncho-dilation ${ }^{34}$. The same combination of changes (increased fres, R5 and R20) are observed in the case of peripheral-airways obstructive pattern, as in the study of Lappas et al. ${ }^{4}$, where IOS measurements pre and post active e-cigarette use revealed a peripheral-airways obstruction pattern. The alteration of fres found in the present study was isolated and did not fall into a specific diagnostic (restrictive or obstructive) pattern. However, it expresses the inhomogeneous airflow distribution ${ }^{33}$, and hence the increased fres that was found could be interpreted as the footprint of the immediate likely irritative effect that SHA from e-cigarettes exerted on the airways.

The trend of FeNO reduction found post exposure was significant in the $0.5 \mathrm{ohm}$ session. This finding is similar to previous studies that found FeNO 
reduction after exposure to active smoking of combustible cigarettes, cigars and e-cigarettes ${ }^{3,4,35,36}$, as well as after passive exposure to second-hand smoke $^{37}$. Furthermore, the only study ${ }^{15}$ that examined FeNO post SHA exposure, although having several methodological differences and limitations (including small sample size, no reported number of efforts or coefficient of variation in FeNO measurements), and most notably the use of a smoking machine, also found a similar trend in FeNO reduction immediately post exposure, however non-significant. It is known that cigarette smoke results in FeNO reduction by activating the down-regulation of NO synthases (inducible and endothelial isoenzymes) ${ }^{38}$ through the nitric oxide it contains ${ }^{39}$. It is also known that the e-cigarette functions by heating the e-cigarette liquid to over $>300$ degrees Celsius ${ }^{19}$ and that nicotine, when heated to $>247$ degrees Celsius, decomposes into nitric oxides and carbon monoxide ${ }^{40}$. Therefore, it is possible that FeNO reduction observed in the current study resulted from the activation of the down-regulation mechanism due to the NO produced from the thermal decomposition of nicotine during e-cigarette use.

Following the recommendations of the e-cigarette manufacturer, a higher power setting was combined with the lower resistance of the 0.5 ohm session. Kosmider et al. ${ }^{41}$ found that setting the e-cigarette to higher power (watts) released significantly higher levels of carbonyls, such as formaldehyde, acetaldehyde and acetone than lower power settings. In addition, this effect was more pronounced in propylene glycol based e-cigarette liquids ${ }^{41}$. Sosnowski et al. ${ }^{19}$ showed that the aerodynamic resistance of e-cigarettes is 10 times higher than for dry-powder inhalers and requires a significantly higher physical effort for inhalation than conventional cigarettes. Therefore, it is possible that regardless of the standardized breathing pattern of the e-cigarette user, due to the different resistance/ power combinations, the SHA produced in each experimental session was slightly different, resulting in the different effects observed in FeNO.

Building on previous research on the health effects of active e-cigarette use, the current findings provide evidence that 30 minutes of passive exposure to e-cigarette emissions result in indications of smallairways irritation, reflected by increased fres and a mild inflammatory reaction of the airways expressed by reduced FeNO.

The current study examined short-term exposure and so conclusions on the potential long-term effects of SHA cannot be made. In terms of developing a scientific research base for evidence-based policy, further studies are needed to examine the possible impact of longer exposure duration and the potential additive effect of repeated exposure.

\section{Strengths and limitations}

The current study had several strengths, including use of a novel e-cigarette device, a cross-over trial study design, a statistically representative sample size of young healthy adults and standardized topography for e-cigarette use by an experienced smoker. In addition, all measurements were performed according to ATS/ERS guidelines.

As the aim of the current study was to explore the passive exposure among young healthy adults, it did not examine the possible effect on patients with respiratory or other medical conditions. Blind control was not possible since participants were able to visually detect the difference in exposure conditions (presence of aerosol cloud), therefore the possible psychological effect of this knowledge was not accounted for.

\section{CONCLUSIONS}

The current study provides evidence that exposure to SHA from e-cigarettes has immediate effects on respiratory mechanics and exhaled inflammatory biomarkers. These findings add to the growing amount of evidence on the immediate health effects of e-cigarettes. Whereas the clinical implications need further assessment, these findings should be taken into account in global policies regarding the regulation of e-cigarette use in public places and in assessments of the effects of SHA on the health of bystanders.

\section{REFERENCES}

1. U.S. Dept. of Health and Human Services, Centers for Disease Control and Prevention, Coordinating Center for Health Promotion, National Center for Chronic Disease Prevention and Health Promotion, Office on Smoking and Health. - [Atlanta, Ga.]. The health consequences of involuntary exposure to tobacco smoke: a report of the Surgeon General. 2006.

2. Kaisar MA, Prasad S, Liles T, Cucullo L. A decade 
of e-cigarettes: Limited research \& unresolved safety concerns. Toxicology. 2016; 365:67-75. doi:10.1016/j.tox.2016.07.020

3. Vardavas CI, Anagnostopoulos N, Kougias M, Evangelopoulou V, Connolly GN, Behrakis PK. Shortterm Pulmonary Effects of Using an Electronic Cigarette. Chest. 2012;141(6):1400-6. doi:http://linkinghub. elsevier.com/retrieve/pii/S0012369212603274

4. Lappas AS, Tzortzi AS, Konstantinidi EM, Teloniatis SI, Tzavara CK, Gennimata SA, Koulouris, NG, Behrakis, PK. Short-term respiratory effects of e-cigarettes in healthy individuals and smokers with asthma. Respirology. 2018;23(3):291-297. doi:10.1111/resp.13180

5. Orellana-Barrios MA, Payne D, Mulkey Z, Nugent K. Electronic Cigarettes-A Narrative Review for Clinicians. Am J Med. 2015;128:674-81. doi: 10.1016/j.amjmed.2015.01.033

6. Fernándes E, Fu M, Martinez-Sanchez J. Exposure to aerosol from smoking-proxy electronic inhaling systems: a systematic review. http://www.who.int/tobacco/industry/product_ regulation/BackgroundPapersENDS1_4november.pdf. Published in Barcelona 30 September, 2016. Accessed 1 December, 2017.

7. Pisinger C, Døssing M. A systematic review of health effects of electronic cigarettes. Prev Med. 2014;69:24860. doi: 10.1016/j.ypmed.2014.10.009

8. American Industrial Hygiene Association ${ }^{\circledR}$. White Paper: Electronic Cigarettes in the Indoor Environment Executive Summary Electronic-cigarettes. Authors: Thursa La, Marcham, C. https://tobacco.ucsf.edu/ sites/tobacco.ucsf.edu/files/u9/AIHA-Electronc Cig Document_Final.pdf. Published 19 October, 2014. Accessed 15 March, 2017.

9. Schober W, Szendrei K, Matzen W, Osiander-Fuchs H, Heitmann D, Schettgen T, Jörres RA, Hermann F. Use of electronic cigarettes (e-cigarettes) impairs indoor air quality and increases FeNO levels of e-cigarette consumers. Int J Hyg Environ Health. 2014;217(6):62837. doi: 10.1016/j.ijheh.2013.11.003

10. Schripp T, Markewitz D, Uhde E, Salthammer T. Does e-cigarette consumption cause passive vaping? Indoor Air. 2013;23(1):25-31. doi: 10.1111/j.1600-0668.2012.00792.x

11. McCauley L, Markin C, Hosmer D. An Unexpected Consequence of Electronic Cigarette Use. Chest. 2012;141(4):1110-3. doi: 10.1378/chest.11-1334

12. Czogala J, Goniewicz ML, Fidelus B, Zielinska-Danch W, Travers MJ, Sobczak A. Secondhand exposure to vapors from electronic cigarettes. Nicotine Tob Res. 2014;16(6):655-62. doi: 10.1093/ntr/ntt203

13. Ghang H. Research gaps related to the environmental impacts of electronic cigarettes. Tob Control. 2014;23 Suppl 2(suppl 2):ii54-8. doi: 10.1136/tobaccocontrol-2013-051480

14. Hess I, Lachireddy K, Capon A. A systematic review of the health risks from passive exposure to electronic cigarette vapour. Public Heal Res Pract. 2016;26(2). doi:10.17061/phrp2621617

15. Flouris AD, Chorti MS, Poulianiti KP, Jamurtas AZ, Kostikas K, Tzatzarakis MN, Hayes W, Tsatsakis AM, Koutedakis Y. Acute impact of active and passive electronic cigarette smoking on serum cotinine and lung function. Inhal Toxicol. 2013;25(2):91-101. doi:10.3109/08958378.2012.758197

16. Flouris AD, Poulianiti KP, Chorti MS, Jamurtas AZ, Kouretas D, Owolabi EO, Tzatzarakis MN, Tsatsakis AM, Koutedakis Y. Acute effects of electronic and tobacco cigarette smoking on complete blood count. FOOD Chem Toxicol. 2012;50:3600-3. doi:10.1016/j.fct.2012.07.025

17. Ballbè M, Martínez-Sánchez JM, Sureda X, Fu M, PérezOrtuño R, Pascual JA, Saltó E, Fernández, E. Cigarettes vs. e-cigarettes: Passive exposure at home measured by means of airborne marker and biomarkers. Environ Res. 2014;135:76-80. doi:10.1016/j.envres.2014.09.005

18. Cheng T. Chemical evaluation of electronic cigarettes. Tob Control. 2014;23(suppl 2):ii11-7. doi: 10.1136/tobaccocontrol-2013-051482

19. Sosnowski TR, Eng D, Kramek-Romanowska K, Eng M. Predicted Deposition of E-Cigarette Aerosol in the Human Lungs. J Aerosol Med Pulm Drug Deliv. 2016;29(3):299-309. doi: 10.1089/jamp.2015.1268

20. Grana R, Benowitz N, Glantz SA. E-cigarettes: a scientific review. Circulation. 2014;129(19):1972-86. doi: 10.1161/circulationaha.114.007667

21. Lerner CA, Sundar IK, Yao H, Gerloff J, Ossip DJ, McIntosh S, Robinson R, Rahman I. Vapors Produced by Electronic Cigarettes and E-Juices with Flavorings Induce Toxicity, Oxidative Stress, and Inflammatory Response in Lung Epithelial Cells and in Mouse Lung. PLoS One. 2015;10(2):e0116732. doi:10.1371/journal.pone.0116732

22. Tackling secondhand tobacco smoke and e-cigarette emissions: exposure assessment, novel interventions, impact on lung diseases and economic burden in diverse European populations (TackSHS). http://tackshs.eu/.

23. Spindle TR, Breland AB, Karaoghlanian N V., Shihadeh AL, Eissenberg T. Preliminary Results of an Examination of Electronic Cigarette User Puff Topography: The Effect of a Mouthpiece-Based Topography Measurement Device on Plasma Nicotine and Subjective Effects. Nicotine Tob Res. 2015;17(2):142-9. doi:10.1093/ntr/ntu186

24. Farsalinos KE, Spyrou A, Tsimopoulou K, Stefopoulos C, Romagna G, Voudris V. Nicotine absorption from electronic cigarette use: comparison between first and new-generation devices. Sci Rep. 2014;4:149-57. doi: $10.1038 /$ srep04133

25. Farsalinos K, Romagna G, Tsiapras D, Kyrzopoulos S, Voudris V. Evaluation of Electronic Gigarette Use (Vaping) Topography and Estimation of Liquid Consumption: Implications for Research Protocol 
Standards Definition and for Public Health Authorities' Regulation. Int J Environ Res Public Health. 2013;10(6):2500-14. doi:10.3390/ijerph10062500

26. Tzatzarakis MN. Results of chemical analysis in "Liqua traditional tobacco" e-cigarette liquid. Laboratory of Toxicology and Forensic Science, University of Crete Medical School Heraklion, Crete, Greece; 2015.

27. ATS/ERS. ATS/ERS Recommendations for standardized procedures for the online and offline measurement of exhaled lower respiratory nitric oxide and nasal nitric oxide, 2005. Am J Respir Crit Care Med. 2005;171:91230. doi:10.1164/rccm.200406-710ST

28. Deveci SE, Deveci F, Açik Y, Ozan AT. The measurement of exhaled carbon monoxide in healthy smokers and non-smokers. Respir Med. 2004;98(6):551-6. doi:10.1016/j.rmed.2003.11.018

29. Oostveen E, MacLeod D, Lorino H, Farre R, Hantos Z, Desager K, Marchal F. The forced oscillation technique in clinical practice: methodology, recommendations and future developments. Eur Respir J. 2003;22:1026-41. doi:10.1183/09031936.03.00089403

30. Miller MR, Hankinson J, Brusasco V, Burgos F, Casaburi R, Coates A, Crapo R, Enright P, Van Der Grinten CPM, Gustafsson P, Jensen R, Johnson DC, Macintyre N, Mckay R, Navajas D, Pedersen OF, Pellegrino R, Viegi G, Wanger, J. Standardisation of spirometry. Eur Respir J. 2005;26:319-38. doi:10.1183/09031936.05.00034805

31. Brashier B, Salvi S. Measuring lung function using sound waves: Role of the forced oscillation technique and impulse oscillometry system. Breathe. 2015;11(1):5765. doi:10.1183/20734735.20514

32. Desiraju K, Agrawal A. Impulse oscillometry: The state-of-art for lung function testing. Lung India. 2016;33(4):410-6. doi:10.4103/0970-2113.184875

33. Berger KI, Pradhan DR, Goldring RM, Oppenheimer BW, Rom WN, Segal LN. Distal airway dysfunction identifies pulmonary inflammation in asymptomatic smokers. ERJ Open Res. 2016;2(4):00066-2016. doi:10.1183/23120541.00066-2016

34. Bickel S, Popler J, Lesnick B, Eid N. Impulse oscillometry: Interpretation and practical applications. Chest. 2014;146(3):841-7. doi:10.1378/chest.13-1875

35. Kougias M, Vardavas CI, Anagnostopoulos N, Matsunaga Y, Tzwrtzi A, Lymberi M, Connolly GN, Behrakis PK. The acute effect of cigarette smoking on the respiratory function and FENO production among young smokers. Exp Lung Res. 2013;39(8):359-64. doi:10.3109/01902148.2013.830654.

36. Lappas AS, Konstantinidi EM, Tzortzi AS, Tzavara CK, Behrakis PK. Immediate effects of cigar smoking on respiratory mechanics and exhaled biomarkers; differences between young smokers with mild asthma and otherwise healthy young smokers. Tob Induc Dis. 2016;14(1):29. doi: 10.1186/s12971-016-0095-6

37. Vardavas CI, Anagnostopoulos N, Kougias M,
Evangelopoulou V, Connolly GN, Behrakis PK. Acute pulmonary effects of sidestream secondhand smoke at simulated car concentrations. Xenobiotica. 2013;43(6):509-13. doi:10.3109/00498254.2012.741272

38. Kharitonov SA, Yates D, Barnes PJ. Increased nitric oxide in exhaled air of normal human subjects with upper respiratory tract infections. Eur Respir J. 1995;8(2):2957. doi:10.1183/09031936.95.08020295

39. Norman V, Keith CH. Nitrogen Oxides in Tobacco Smoke. Nature. 1965;205:915-6.

40. National Center for Biotechnology Information. PubChem Substance and Compound database: Nicotine CID=89594. https://pubchem.ncbi.nlm.nih.gov/compound/ nicotine\# section=Decomposition $\&$ fullscreen=true. Accessed 12 August, 2017.

41. Kosmider L, Sobczak A, Fik M, Knysak J, Zaciera M, Kurek J, Goniewicz ML. Carbonyl compounds in electronic cigarette vapors: effects of nicotine solvent and battery output voltage. Nicotine Tob Res. 2014;16(10):1319-26. doi:10.1093/ntr/ntu078
CONFLICTS OF INTEREST

Author Panagiotis K. Behrakis is the Editor in Chief of TPC and that there are no conflicts of interest with this current work. The rest of the authors also have completed and submitted an ICMJE form for disclosure of potential conflicts of interest. The authors declare that they have no competing interests, financial or otherwise, related to the current work.

FUNDING

This project received funding from the European Union's Horizon 2020 Research and Innovation Programme, under grant agreement No.681040. Esteve Fernandez was supported by the Ministry of Research and Universities, Government of Catalonia (2017SGR319). This manuscript reflects the authors' views only and the European Commission is not responsible for any use that may be made of the information it contains.

PROVENANCE AND PEER REVIEW

Commissioned;

externally peer reviewed 